\title{
A case study of floating offshore wind park in the Mediterranean
}

\author{
J. Milagro Serrano, J.A. Domínguez-Navarro, J.S. Artal Sevil, and R. Dufo López \\ Department of Electrical Engineering \\ Escuela de Ingeniería y Arquitectura. Universidad de Zaragoza \\ C/ María de Luna, 3. 50018 Zaragoza \\ E-mail: juanmilagro1@gmial.com, jadona@unizar.es, jsartal@unizar.es, rdufo@unizar.es
}

\begin{abstract}
This work presents a case study of floating offshore parks in the Mediterranean Sea. There are several constraints that determinate the location of the park: the availability of a sufficient wind resource, environmental laws, sea routes, the seabed depth (what will condition the whole project), the proximity of the necessary infrastructures and a social constraint. The Mediterranean seabed depth conditions the structure of the wind farm, which consists of the selection of the most adequate platform, the configuration of the mooring lines of those platforms, the type of wind turbine to install and their layout. The calculation of the power production is based on SIMAR data set, supplied by Puertos del Estado. A study of the wake effect produced by wind turbines based on the Jensen's model has also been carried out. The power extraction system consists of three parts: a $33 \mathrm{kV}$ line for the inter-array cables, an offshore substation located in the middle of the wind farm and a $220 \mathrm{kV}$ line for the connection to shore.

The conclusions obtained from this study are clear: this kind of projects are available in our country, and they are quite profitable if they are structured properly, though its profitability is lower than in other countries. In any case, there is still quite uncertainty concerning to that, a fact mainly motivated by the lack of a specific legislation in Spain.
\end{abstract}

\section{Key words}

Floating offshore wind park, economic profitability, wind energy production.

\section{Introduction}

Parallel to the development of onshore wind, offshore wind has also been developed in giant steps, although its origins are closer than those of land-based wind turbines (the first offshore wind farm dates back to 1991, in Denmark). This development in wind farms was motivated by various causes, such as the higher speed and frequency of offshore wind, the lower surface roughness, the lower air turbulence or the fact that the best land-based wind sites are already being exploited. And if the trend of onshore parks is to install increasingly powerful wind turbines, in offshore parks this trend is even more accentuated. To quantify this trend, the first of these parks had wind turbines of $450 \mathrm{~kW}$ unit power, while currently there are $8 \mathrm{MW}$ turbines in operation. In addition, there are currently developed $10 \mathrm{MW}$ turbines ready for commercialization, and projects in machine development that already exceed $10 \mathrm{MW}$ of rated power.

Therefore, at the end of 2016 and according to WindEurope data [1], offshore wind power installed in Europe was 12,631 MW, a figure that is the result of large investments in this technology by countries such as Germany or the United Kingdom (among both have more than $70 \%$ of European offshore wind power). In addition, according to the forecasts of this same association, the trend in this year is to install twice as much power as the previous year, so this figure will continue to increase at a very fast pace.

In the Spanish case, the great depth of the seabed in waters near the coast is prevented for the moment the installation of this type of wind farms. Since the offshore wind farms installed to date had wind turbines anchored to the seabed, it is easy to understand the reason for the absence of this type of wind farm in our country.

The present work will focus on studying the possibilities of offshore wind generation in the waters of the Mediterranean Sea.

\section{Floating offshore park location}

On the Mediterranean coast, the Alboran Sea is chosen, because it is the Spanish Mediterranean area with the largest wind resource.

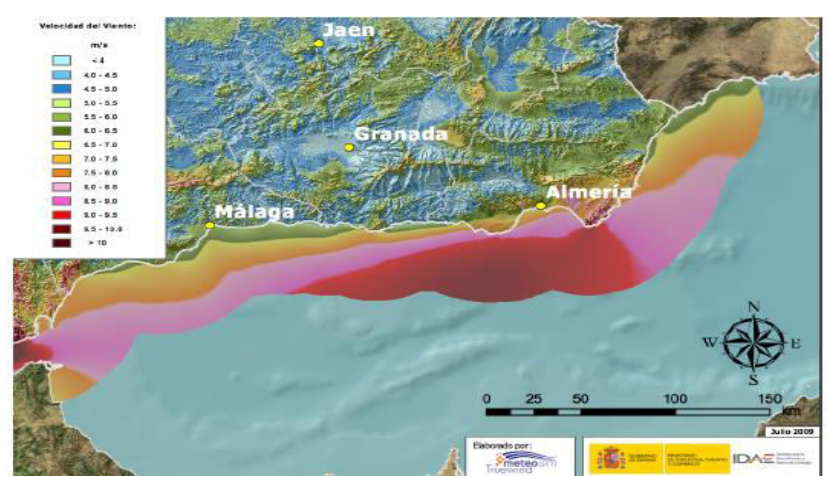

Fig. 1. Average wind speed in the Alboran Sea at $80 \mathrm{~m}$ height (Source: [2]) 
In the first place, we must bear in mind that the Alboran Sea has a great biodiversity that must be respected. A very visual way of showing these restrictions is through the "Marine environmental zoning map for wind farms" prepared by the IDAE [3].

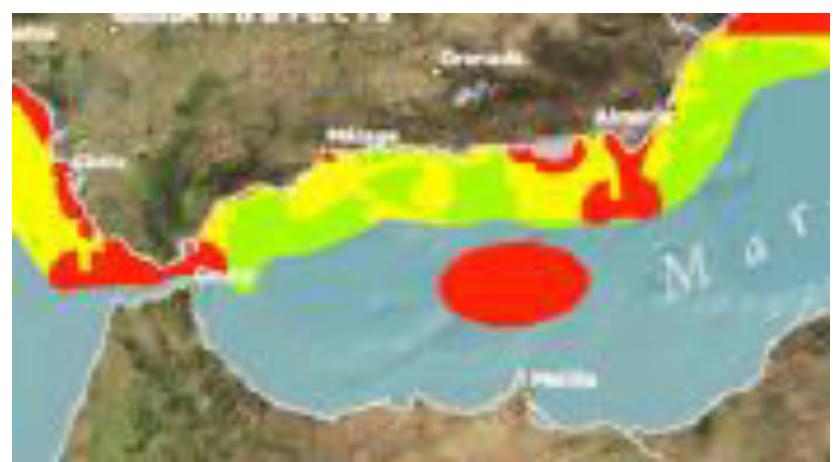

Fig. 2. Marine environmental zoning for wind farms in Spain (Source: [3])

The Mediterranean Sea is crossed by a multitude of maritime routes that cannot be interrupted by projects such as wind farms, so these routes will suppose exclusion zones for the location of the park, Fig. 3.

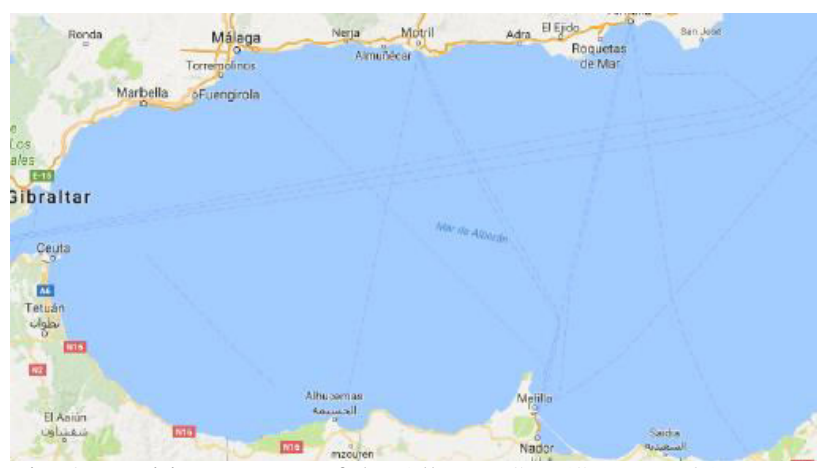

Fig. 3. Maritime Routes of the Alboran Sea (Source: [4])

The area 30 in Fig. 3 is the area with the highest speed of wind that meets the previous restrictions. Within the chosen area, the park will be located as close as possible to the point of connection on the coast; this is the upper left corner. Therefore, the park is finally located inside a rectangular surface of $17.32 \mathrm{~km}^{2}$, whose four corners have the following coordinates: $4^{\circ} 35.1^{\prime} \mathrm{W}-36^{\circ} 15^{\prime} \mathrm{N} ; 4^{\circ} 32.2^{\prime}$ $\mathrm{W}-36^{\circ} 15^{\prime} \mathrm{N} ; 4^{\circ} 35.1^{\prime} \mathrm{W}-36^{\circ} 12.84^{\prime} \mathrm{N}$; and $4^{\circ} 32.2^{\prime} \mathrm{W}$ $-36^{\circ} 12.84^{\prime} \mathrm{N}$.

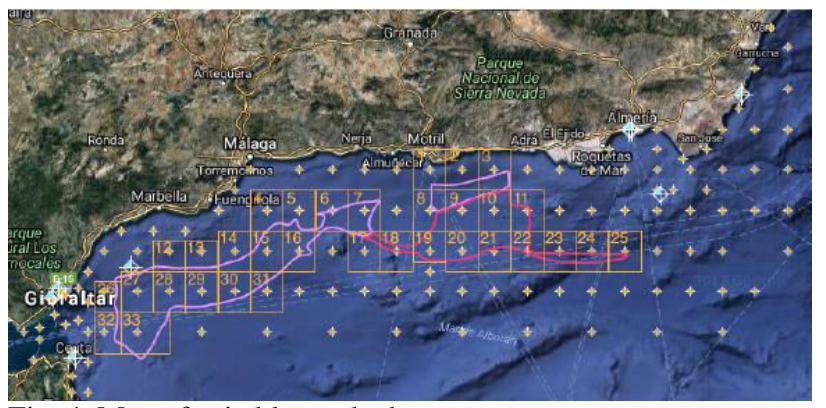

Fig. 4. Map of suitable meshed areas

\section{Floating offshore structure}

There are three types of floating structures, which are exposed below, differentiated according to how they achieve the stability of the structure:

\section{A. Platforms stabilized by ballast (1)}

Also called SPAR. They consist of a very elongated buoy with a ballast in its lower part and anchored to the sea bottom, usually by catenary lines (although they can also be anchored by tensioned lines), so that it achieves stability by lowering the centre of gravity of the structure. In addition, due to its elongated shape, the movement of the tides hardly affects the structure. On the other hand, due to the great weight of its ballast, it manages to minimize the movement of the structure due to the action of wind and waves. However, it is more sensitive to marine currents.

\section{B. Platforms stabilized by mooring lines (2)}

Also called TLP (Tension Leg Platform). They consist of platforms anchored to the seabed by tensioned mooring lines that provides stability to the structure. The great problem that this type of structures presents are the variations of tension that are generated in the moorings by the action of the tides. In addition, the installation of this type of structures is also quite complex.

\section{Platforms stabilized by floatability (3)}

Also called Barge (Barge). They consist of platforms anchored to the seabed by catenary lines whose stability is based on the inertia of buoyancy (as in the case of barges). A great advantage of this type of structure is that it allows the assembly of the wind turbine in port. In the same way, it is possible to tow a wind turbine already installed from the park to the port to carry out maintenance works. This supposes a substantial decrease in complexity and the costs of these procedures.

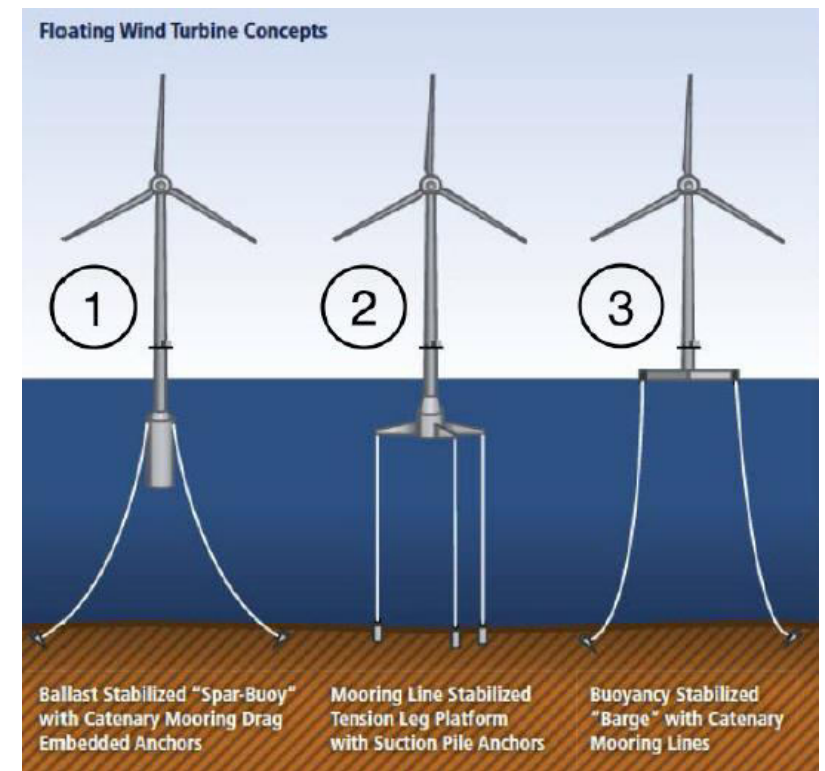

Fig. 5. Types of floating platforms for marine wind turbines (Source: [5]) 
In the case of semi-submersible platforms, the main task of the moorings is to maintain the position of the platform and prevent it from drifting, although they also contribute to the stability of the structure due to its own weight. The typical configuration of the anchoring lines for semisubmersible platforms is catenary lines, type 3 , so that a large part of them is supported on the seabed horizontally, as can be seen in Fig. 6.

The standard configuration is 3 lines of funding for each wind turbine, but due to the great depth of the site and the configuration of the chosen mooring lines, too many kilometers of chain would be needed, which would greatly increase the costs of the project. Therefore, a new configuration [6] consisting of the formation of groups of 3 platforms arranged forming a triangle will be used, which are linked together by chains and share the 3 lines of anchoring. In this way, a savings of $10 \%$ is achieved in the CAPEX of the project.

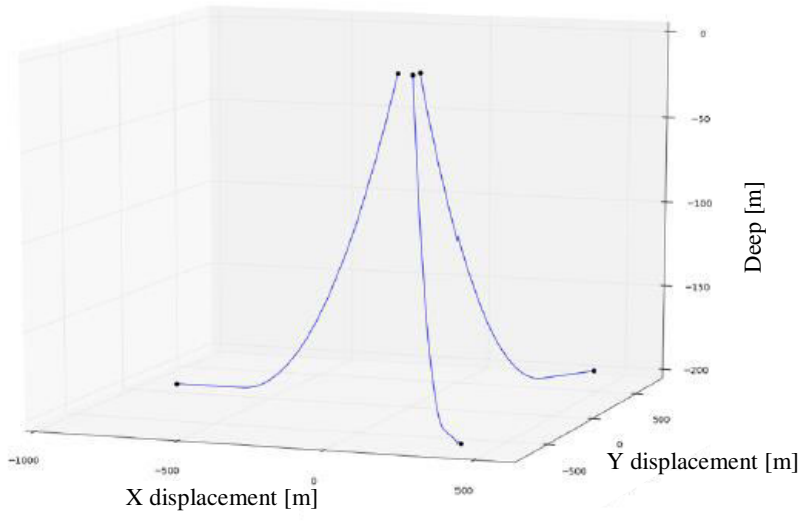

Fig. 6. Catenary lines (z axis: $50 \mathrm{~m}$ grid, $\mathrm{x}$ and $\mathrm{y}$ axis: $500 \mathrm{~m}$ grid)

\section{Wing generator and park layout}

The Gamesa model G132-5.0 MW wind turbine is chosen, as it is a wind turbine that is more suitable for the local wind conditions. In addition, it is a model already tested with satisfactory results [7].

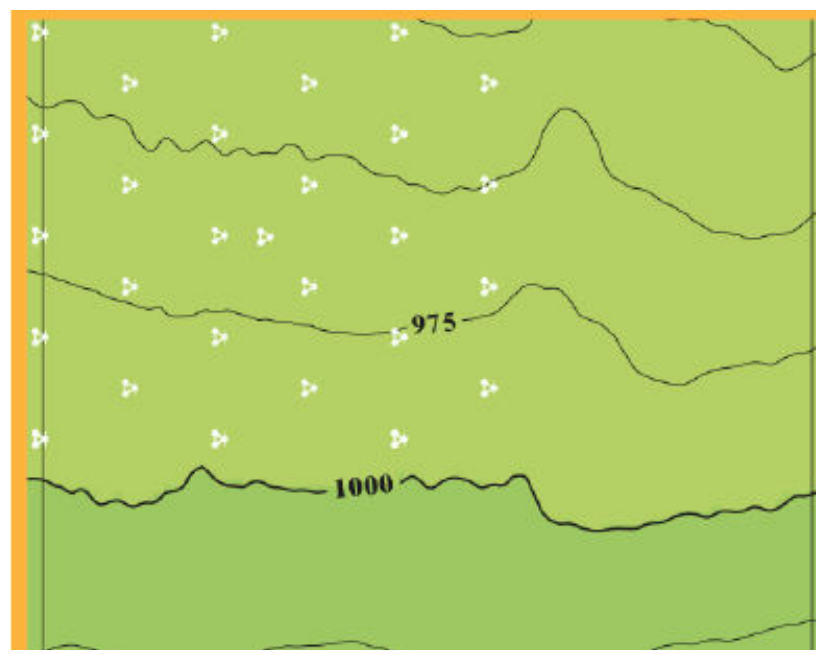

Fig. 7. Layout of the park
The layout of the park can see in Fig. 7, with a separation of 1000 meters between wind turbines of the same row and 866 meters between adjacent rows. The substation will be placed on the floating platform at the centre of the park, in order to reduce the costs and losses of the MV wiring of the park interconnections.

\section{Wind power production}

For the calculation of wind turbine production, the SIMAR wind data series provided by Puertos del Estado [2] is available, and data between 2007 and 2016 will be used. The SIMAR point closest to the location of the park is 2030074 , whose coordinates are $4^{\circ} 30^{\prime} \mathrm{W}-36^{\circ} 10.2^{\prime}$ N.

First, a vertical extrapolation, Fig 8, of the wind speed is carried out, because the received data corresponded to a height of $10 \mathrm{~m}$ above the sea surface and the wind turbine has a bushing height of $140 \mathrm{~m}$., afterwards the probability distribution of the wind was obtained, Fig. 9.

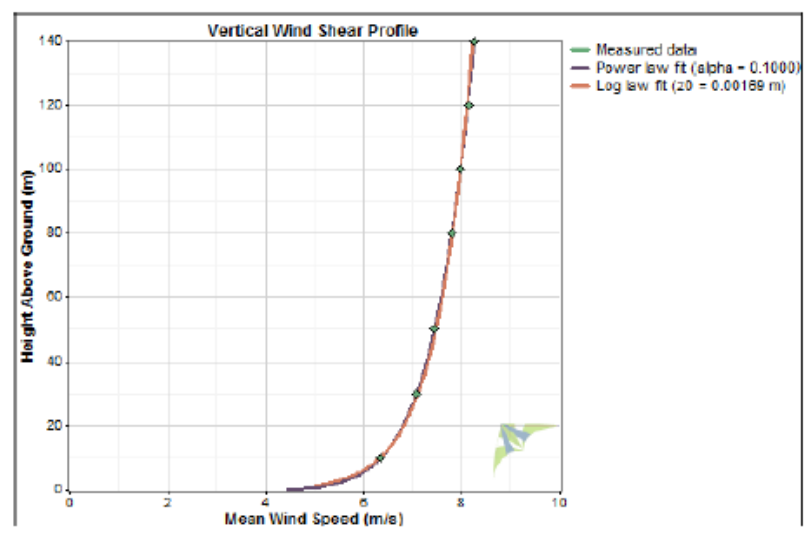

Fig. 8. Vertical profile of the wind at the site

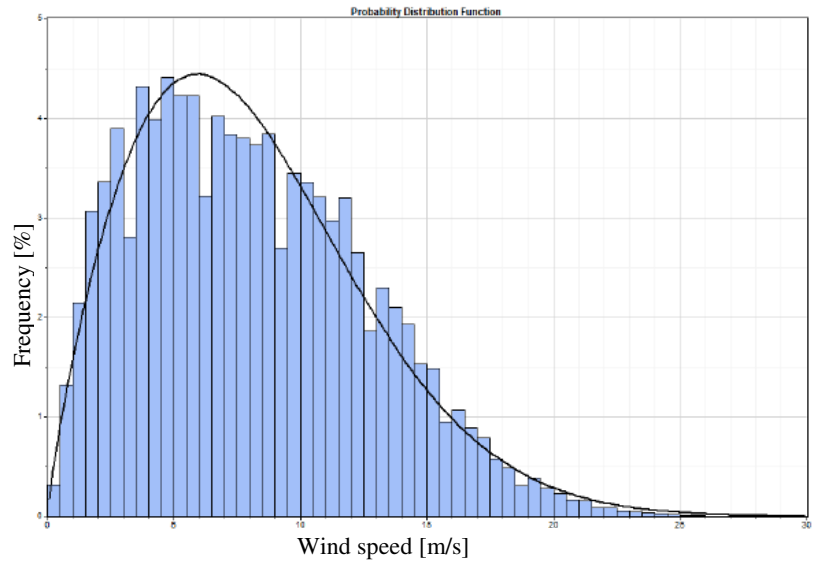

Fig. 9. Distribution of probability at the site

All the wind turbines modify the flow of wind that crosses them when extracting the energy that it contains, producing behind it a turbulence called the wake effect. In marine sites, environmental turbulence is much lower than in terrestrial sites; consequently, the wake effect is much more noticeable in the farm. This translates into obvious losses that will have to be taken into account when calculating production. For this, the model of Jensen [8,9] will be applied, which calculates the wind 
speed within a wake at a distance $\mathrm{x}$ of the wind turbine that causes this disturbance.

Table I. - Annual production by rows and losses by wake effect

\begin{tabular}{|c|c|c|c|c|}
\hline & \multicolumn{2}{|c|}{ Annual production (MWh) } & \multicolumn{2}{c|}{ Losses by wakes } \\
\hline Row & No wakes & Wakes & MWh & $\%$ \\
\hline 1 & $98.045,64$ & $98.045,64$ & 0,00 & $0,00 \%$ \\
\hline 2 & $78.436,51$ & $78.436,51$ & 0,00 & $0,00 \%$ \\
\hline 3 & $98.045,64$ & $83.337,62$ & $14.708,03$ & $15,00 \%$ \\
\hline 4 & $78.436,51$ & $66.670,09$ & $11.766,42$ & $15,00 \%$ \\
\hline 5 & $98.045,64$ & $80.311,72$ & $17.733,93$ & $18,09 \%$ \\
\hline 6 & $78.436,51$ & $64.249,37$ & $14.187,14$ & $18,09 \%$ \\
\hline Total & $529.446,47$ & $471.050,95$ & $58.395,52$ & $11,03 \%$ \\
\hline
\end{tabular}

The retribution considered for the generated energy will be an average of the compensation that currently has different offshore wind projects in different countries Europeans [10], obtaining a retribution of $139.85 € / \mathrm{MWh}$.

Thanks to these results, the project's NPV and IRR, or the RCSDmean and the profitability of the shareholders can also be obtained in Table II.

Table II. - Project financial ratios

\begin{tabular}{|c|c|}
\hline RCSDmean & 1.41 \\
\hline VANproyecto $(€)$ & $195.524 .806,94$ \\
\hline TIRproyecto & $8.29 \%$ \\
\hline TIRaccionistas & $22.59 \%$ \\
\hline
\end{tabular}

\section{Conclusion}

Analyzing the information gathered during the realization of this work, the first impression that can be obtained is that the introduction of offshore wind in Spain will not be as "easy" as in other countries such as the United Kingdom, Germany or Denmark. This is due to a wind resource that is noticeably lower than in these regions and to a slope of the seabed that immediately makes it very deep. In addition, the fact of not having specific legislation in Spain regulating the remuneration of energy from this source covers this situation with a blanket of uncertainty. However, this work has shown that this type of project is viable off our coasts, both in technical terms and in financial terms, if we study each of the aspects related to sufficient depth.

\section{Acknowledgement}

The authors would like to thank the support of Government of Aragon with FEDER funds.

\section{References}

[1] Pineda, I., Pierre Tardieu, W., \& Miró, L. (2017). 2016 European statistics Wind in power WindEurope Business Intelligence Aloys Nghiem (Installation highlights) Ariola Mbistrova (Financing highlights) Courtesy of Senvion Gmbh. Retrieved from https://windeurope.org/wp-content/uploads /files/aboutwind/statistics/WindEurope-Annual-Statistics2016.pdf
[2] Conjunto de datos SIMAR, Puertos del Estado (1958-2017) [Base de datos]. Prediccion de oleaje, nivel del mar; Boyas y mareografos | puertos.es. (n.d.). Retrieved from http://www.puertos.es/es-

es/oceanografia/Paginas/portus.aspx

[3] IDAE | Gobierno de España | Atlas Eólico de España. (n.d.). Retrieved from http://atlaseolico.idae.es/

[4] Google Maps. (n.d.). Retrieved from https://www. google.es/maps/

[5] Global Carbon Capture and Storage Institute. (n.d.). Retrieved from http://www.globalccsinstitute.com/

[6] Goldschmidt, M., \& Muskulus, M. (2015). Coupled mooring systems for floating wind farms. Energy Procedia (Vol. 80). Elsevier B.V. https://doi.org/10.1016 /j.egypro.2015.11.429

[7] Gamesa Offshore Cutting edge technology solutions. (n.d.). Retrieved from http://www.gamesacorp.com/recursos/doc /productos-servicios/aerogeneradores/catalogo-offshoreeng.pdf.

[8] Jensen, N. O. (1983). A note on wind generator interaction. Riso National Laboratory Roskilde, 1-16. https://doi.org /Riso-M-2411

[9] Shakoor, R., Hassan, M. Y., Raheem, A., \& Wu, Y. K. (2016). Wake effect modeling: A review of wind farm layout optimization using Jensen's model. Renewable and Sustainable Energy Reviews, 58, 1048-1059. https://doi.org /10.1016 /j.rser.2015.12.229

[10] Serrano González, J., \& Arántegui, R. L. (2015). The regulatory framework for wind energy in EU Member States - Part 1 of the Study on the social and economic value of wind energy. JRC Scientific and Policy Reports. https://doi.org/10.2790/282003 